\title{
Publisher Correction: Dynamic photovoltaic building envelopes for adaptive energy and comfort management
}

Bratislav Svetozarevic (D), Moritz Begle, Prageeth Jayathissa, Stefan Caranovic, Robert F. Shepherd (iD, Zoltan Nagy (D), Illias Hischier (D), Johannes Hofer (D) and Arno Schlueter (D)

Correction to: Nature Energy https://doi.org/10.1038/s41560-019-0424-0, published online 8 July 2019.

In the version of this Article originally published, a technical error led to the data in Fig. $7 \mathrm{~b}$ displaying wrongly; this has now been corrected. The original and corrected figures are shown below.
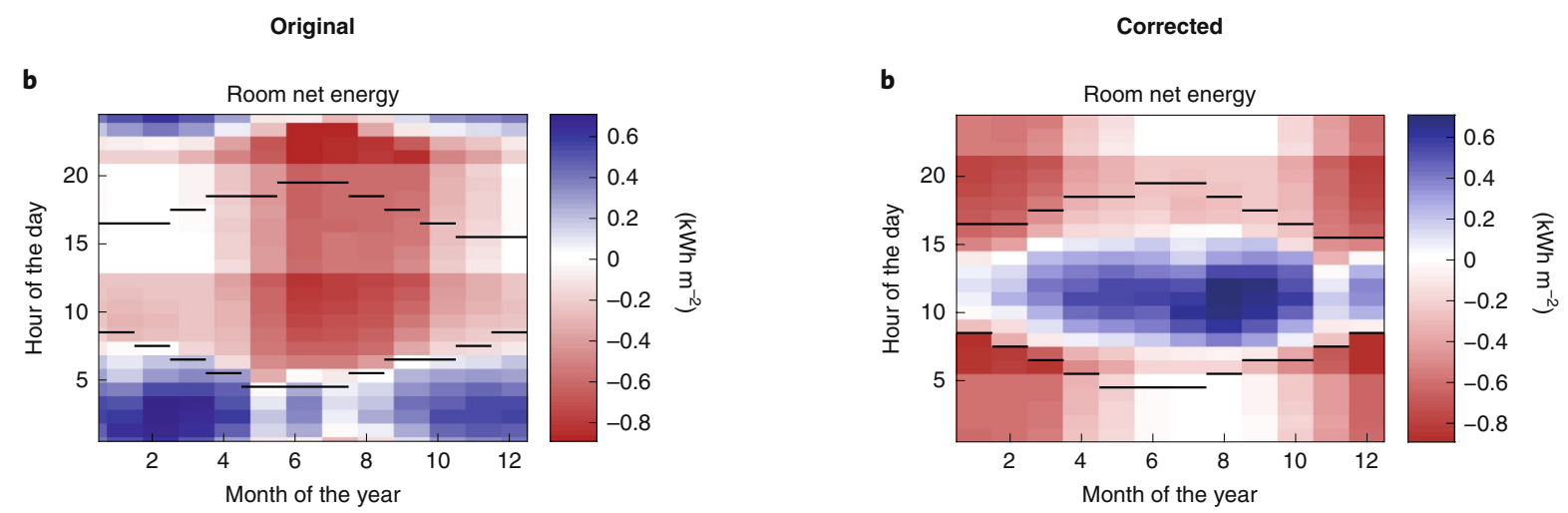

Fig. 7b | Original and corrected.

Published online: 22 July 2019

https://doi.org/10.1038/s41560-019-0447-6 